\title{
The Application of Chinese Traditional Culture in the Animation Scene Design
}

\author{
Lina Shang \\ Huanghe Science and Technology College \\ Zhengzhou, China 450046
}

\begin{abstract}
As a kind of visual art, the animation scene design is not only the development background of the story, but also the reflection of the animation characters and the visual expression of story line with the development of time. Therefore, the animated films with national cultural connotation are able to be favored and admired by the world audiences. We can make full use of Chinese traditional culture elements, such as ink painting, paper cutting, Chinese opera, shadow puppet and Chinese architecture, in producing animated films. We can make full use of traditional decorative patterns in its scene creation. For example, Lingxiao Hall in "Havoc in Heaven" has imitated the traditional Chinese architectural form; the shadow puppet animation of "Peach Garden" has used shadow puppet, Chinese painting, paper cutting, bold freehand brushwork and other traditional cultural elements.
\end{abstract}

Keywords-China; traditional culture; scene design; application

\section{INTRODUCTION}

We have been very particular about national exploration since the beginning of our animation creation. The first animated feature film of "Iron Fan Princess" created by Wan Brothers has focused on the aspect of nationalization. Toady, what we need to explore in our animation creation is that how can we explore the issue of modernization based on the nationalization.

As a kind of visual art, the animation scene design is not only the development background of the story, but also the reflection of the animation characters and the visual expression of story line with the development of time. Therefore, the animated films with national cultural connotation are able to be favored and admired by the world audiences. We can make full use of our traditional culture elements, such as ink painting, paper cutting, Chinese opera, shadow puppet and Chinese architecture, in producing animated films. We can make full use of traditional decorative patterns in its scene creation. For example, Lingxiao Hall in "Havoc in Heaven" has imitated the traditional Chinese architectural form; the shadow puppet animation of "Peach Garden" has used shadow puppet, Chinese painting, paper cutting, bold freehand brushwork and other traditional cultural elements. In the scene design of

Fund source: 2015 Annual Youth Project of Humanities and Social Sciences Research of Henan Province Education Department; 2015-QN388

Project Name: Application and Research of Yuju Opera Art in the Creation of 2D Animation.
"Peach Garden", designers mainly use the expression patterns of elaborate-style painting and ink painting. Pink peach blossom petals swirl around beautiful ink mountains and rivers. The fairyland atmosphere makes people relaxed and happy.

The Chinese opera animation of Zuo Wen Zhang created by Henan Jufeng Animation Studio (a student society of art design in my college) used the expression form of Chinese opera stage in entire scene creation, and also re-integrated and extracted Chinese opera elements. The film fully reflects the culture of Chinese opera and the unique charm of animation. Therefore, it is very important to integrate Chinese traditional culture and arts in the creation of animation scenes. The wide application of Chinese traditional culture and arts elements, such as Chinese calligraphy, seal cutting, Beijing opera, shadow puppet, martial arts, traditional musical instruments and ancient patterns, in the creation of Chinese animation scene can fully reflect the national features of Chinese animation.

\section{ThE WidE APPLICATION OF TRAditional ARTS EXPRESSION TECHNIQUES IN CHINESE TRADITIONAL ANIMATION SCENE}

\section{A. The Application of a Variety of Local Art Expression Techniques}

The Chinese traditional animation scene design has inherited the essence of Chinese painting art and folk art. There are various expression patterns, such as ink painting, shadow puppet, New Year paintings, paper cutting, clay sculpture, etc. The means and materials used in the creation of animation art directly determine the final presented style and characteristics of work and film language, thus giving a unique aesthetic enjoyment. The reason why Chinese traditional animation plays an important role in the world animation circle is because it is rooted in local culture, and its artistic expression techniques have strong national characteristics.

In the creation of Chinese traditional animation, we should attach great importance to the innovation on techniques of expression and picture form. In addition to ink painting, paper cutting, puppet animation and other main expression patterns, we also have used New Year paintings, murals, rock paintings, portrait brick of Han Dynasty and other art forms, and have made impressive achievements. 
For example, the animated film of "Butterfly Spring" is themed by minorities in Yunnan. The scene of this film highlights the style and features of Yunnan's heavy-colored decorative paintings. The scene of the film describes mountains and streams in Dali, sightseeing of Erhai Lake and houses of Bai people. The pictures are extremely beautiful, with elegant color and of perfect decorative composition, and have a very high aesthetic value ${ }^{1}$.

\section{B. The Concise and Decorative Composition}

The scene design of Chinese traditional animation is deeply influenced by Chinese painting and folk decorative arts, so it is particular about form beauty of pictures. The design of Chinese traditional animation has a great difference with the mainstream animation design style of Japan and the United States. We lay more emphasis on the decorative beauty of pictures, rather than special depth-seated level or camera motion, so that Chinese traditional animation scene composition also has its unique aesthetic features. In the composition of Chinese traditional animation scene, we extensively use the two unique characteristic picture forms: eye-level composition and overlook composition. In addition, in space scene design, we largely use the composition methods of traditional theatrical stage, concise, summary and with unique national flavor.

\section{The Application of the Space Perspective Method Without Restriction}

In Chinese traditional painting, we often use the scatterplot perspective method to organize the picture content, so that the author is not limited to the fixed domain. There is no unified perspective vanishing point in the whole picture. The picture content is not subject to the restriction of objective scenery. The author can arrange composition elements according to the subjective creation intention. In scene design of Chinese traditional animation, we generally use the scatterplot perspective mean to deal with the picture layout. It is an important feature in picture form of Chinese traditional animation.

In the animation scene design, we use the scatterplot perspective to form the diversity of picture viewpoint, and this method can integrate visual contents unable to express into picture and provide ample space for the author's artistic creation and the performance of art expressive force. This perspective method can make picture form planar and the author can ignore the rule of foreshortening effect, which make it convenient for author's multi-view performance on time and space in the same picture. The effect can show a very impressionistic style of aesthetic characteristics. At the same time, it provides flexible means for the application of film language and the performance of plot development. At the beginning of the short animated film of "Beauty Contest", the author has used several full-length shots to describe the passing of the king in a sedan in the street. The picture has adopted the scatterplot perspective method to include various

\footnotetext{
${ }^{1}$ Pang Xunqin. Research on Ancient Chinese Decorative Painting. Shanghai: Shanghai People's Fine Arts Publishing House, 1982.
}

daily lives in the composition. A mere few shots have vividly showed all kinds of people's lives and well described the background of the story.

\section{The Stylized Color Expression}

In the animation scene design, color has played a role in creating the atmosphere of the scene, reflecting the theme of the work and expressing the space sense of picture. The treatment of color relations in the scene also plays an important role in the overall art style. The color system of Chinese traditional animation scene is influenced by the traditional aesthetic thought, especially the folk decoration arts, has a high degree of decorative features and a stylized characteristic. The "stylized" expression technique in the traditional Chinese art form is a summary of a traditional Chinese art rule and a crystallization of art experience. The stylization is its prominent feature, and it has a positive meaning for inheritance of art style, division and reproduction of schools.

\section{DigGING OUT TRADITION AND USING FOR REFERENCE AND INHERITANCE}

The reason why Chinese traditional culture and arts endure after suffering several thousand years of wind and rain is because it contains a wealth of Chinese culture. They are not just simple forms of arts. In inheriting Chinese traditional culture and arts, we can not simply copy ancient tradition things directly. If we only stay on the level of using the forms of traditional culture and arts, and do not consider the cultural connotation of traditional arts, our animation works will be "neither fish nor bowl"2.

We need to understand the national culture before we dig out the connotation of the national culture. It can be said that Chinese culture is extensive and profound. Our nation has experienced the influence of traditional Confucianism and contention of a hundred schools of thought, and the washing of thousands of years of history before the formation of the unique Chinese culture and national spirit. It is a complete cultural system which contains unity and solidarity, the patriotic spirit of loyalty, industrious and brave, and plain living attitude, strong will of self-improvement and tenacious struggle, interpersonal concept of unity and mutual aid, the value ideas of regarding the world as a community, the filial piety of respecting the aged and parents, and the humble and cautious noble characters. In addition, our minorities also have a lot of unique national culture and quality, which are worthy of publicity and reference by animation creators.

With the continuous development of the animation scene design, many styles of design methods have been developed and matured. Designers can blend Chinese traditional culture in the animation scene to form new animation styles. We can not only borrow Chinese traditional visual elements but also play our subjective initiative and boldly make innovation to develop the potential ability on Chinese animation scene design. The personality of the scene is the designer's

\footnotetext{
${ }^{2}$ Lv Hua. Future Development of Chinese Animation from the View of Classic Animated Characters. Hubei Academy of Fine Arts, 2007, p25. Chinese Excellent Master's Degree Paper Database [DB].
} 
subjective orientation and original view due to designer's own personality. This personalized design is in accord with the aesthetic and aesthetic fashion requirements in certain times and social scope. Based on thorough understanding of the connotation of traditional culture, designers recombine elements and seek inspiration and find personality in the creation, and then deepen and perfect design concepts in seeking new and personalized visual effect.

\section{A. Digging out Modeling Elements from the Traditional Culture}

With the diversified development trend, the animation scene will be more cultural and social with the integration of Chinese traditional culture. It will be easier to be widely accepted and recognized, and be full of vitality. It is necessary to dig out the essence and connotation of the Chinese culture in design. Therefore, it is not necessary to rigidly adhere to the original features of the traditional culture elements. The purpose is to convey the charm of the national style.

In China, we pay attention to internationalization and diversification in animation creation and digging out our traditional modeling elements. We can form a sustainable competitiveness only by standing on local culture. Localization refers to the local, personalized and traditional characteristics of certain nation and culture or the localized integration of foreign culture. However, the real localization is not unalterable. It is different with tradition. It is a modern concept. It is "local" but not conservative. It is an open system. It also attaches importance to the cultural and social driving force of "change" and the absorption and digestion of foreign culture. It pays attention to the organic combination of traditional culture and modern civilization, so as to continue to revise them in the development course. Therefore, the region where a designer lives in determines the cognitive concept of the design. If a designer can make animation scene based on local culture, the scenes of the designer can express the ideas and concepts of his/her nation. Through these works, audiences can understand the context of the development of the national history. From the development of art, modern design ideas and expression forms has certain relationship with Chinese traditional visual modeling elements. Of course, the re-production of design elements is not limited to the old modeling elements. It also has an important significance to improve and recreate all modern visual modeling elements on the "localization" of animation scene.

\section{B. Having the International View}

We should not only emphasize the inheritance of traditional culture and arts in Chinese animation, but also pay attention to draw on foreign advanced animation experience, so that the traditional art can mutually tolerated with the world culture. From the rapid development, Japanese animation works are favored by the global audiences. The reason is that Japanese works precisely combine their national culture with international ideas. First, their animation scripts not only select traditional folk myths and stories as theme to show their nation characteristics, but also reveal the concern of contemporary international issues, such as the nature of human nature of good and evil thinking, the world's ecological environment after globalization, and so on Japanese animation scripts capture the focus of the world's audience. The audiences of every country can find their interested things. In the development of animation, Japan has used the American industrialized animation development mode for reference, and formed their own animation industrial mode and mechanism in constantly seeking the needs of the work market.

We cannot close our doors to the rest of the world in the development of animation. We should open our eyes to see the world. Overall, we should master modern animation development rules and absorb foreign classic works and excellent myths and stories in writing scripts to expand our creative ideas. As for style of animation, we can use foreign excellent culture patterns and form a diversified and characteristic creation style. In the application of technologies, we can introduce advanced animation technologies and show the power of modern technologies in our traditional Chinese animation. For the aspect of industrial development of animation, we can use foreign perfect industrial animation development mode and constantly open up domestic and foreign two markets. Only by adhering to the nationalization and following the pace of internationalization, can we make our animation accepted by the world and our animation really go to the world and stand in the global animation circle.

Since 1990s, our animation creation has been influenced by that of the United States and Japan and lost our way in the upgrading process of animation creation methods. The core problem of Chinese animation creation is the lack of national culture. But at present, simply imitating the successful mode of traditional animation can not achieve the revitalization. Compared with the production conditions of Chinese traditional animation, contemporary animation creation has the following differences. First, animation creation means are digital. Whether it is a two-dimensional animation or a new three-dimensional animation, the computer-based graphics and image technologies have provided us with powerful and efficient production tools. The technological changes make animation art works show distinct aesthetic features. Second, the animation media are diversified. Channels for people to access to animation are not only limited to TV and movies. People can use mobile terminals, such as internet and smart phones to watch animated films, which makes functions of animation diversified. There are contemporary animation works for the pursuit of pure art value, and works for entertainment of audiences, and works combined with forms of games, advertising and etc.

We should pay attention to the production of animated scenes in order to promote our works in the world. We should first dig out art treasures of our nation, learn and use tradition and make creation, so that our animation works with Chinese characteristics can be promoted in the world art circle. 


\section{REFERENCES}

[1] Pang Xunqin. Research on Ancient Chinese Decorative Painting. Shanghai: Shanghai People's Fine Arts Publishing House, 1982.

[2] Lv Hua. Future Development of Chinese Animation from the View of Classic Animated Characters. Hubei Academy of Fine Arts, 2007, p25. Chinese Excellent Master's Degree Paper Database [DB]. 